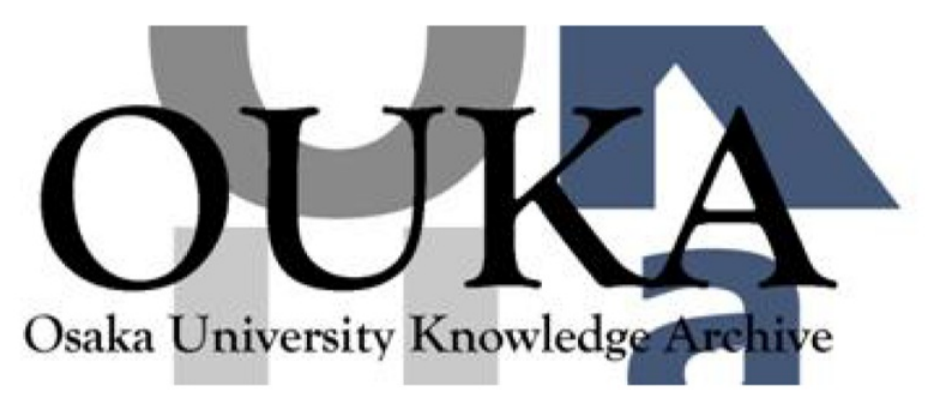

\begin{tabular}{|c|l|}
\hline Title & $\begin{array}{l}\text { The great East Japan earthquake and out-of- } \\
\text { hospital cardiac arrest }\end{array}$ \\
\hline Author(s) & $\begin{array}{l}\text { Kitamura, Tetsuhisa; Kiyohara, Kosuke; Iwami, } \\
\text { Taku }\end{array}$ \\
\hline Citation & $\begin{array}{l}\text { New England Journal of Medicine. 369(22) } \\
\text { p. 2165-p. } 2167\end{array}$ \\
\hline Issue Date & $2013-11-28$ \\
\hline oaire:version & VoR \\
\hline URL & https://hdl. handle. net/11094/78417 \\
\hline rights & $\begin{array}{l}\text { ○ 2013 Massachusetts Medical Society. Reprinted } \\
\text { with permission. }\end{array}$ \\
\hline Note & \\
\hline
\end{tabular}

Osaka University Knowledge Archive : OUKA

https://ir. Library. osaka-u. ac. jp/

Osaka University 
ations (CARE). 2012-2013 (http://clinicaltrials.gov/ct2/show/ NCT01663350).

4. Idem. Investigation of the impact of noninvasive prenatal testing for fetal aneuploidy on utilization of prenatal diagnostic procedures and pregnant women's views. 2013 (http://clinicaltrials.gov/ct2/show/NCT01708746).

DOI: 10.1056/NEJMc1311604

THE AUTHORS REPLY: The studies cited by Ashwood and Palomaki regarding cfDNA noninvasive prenatal testing techniques certainly were necessary to demonstrate the sensitivity and specificity of the various techniques for the detection of the studied fetal trisomies, and the studies were conducted efficiently. We maintain, however, that these exploratory studies alone do not provide information on all the performance characteristics (positive and negative predictive values) of the testing that is sufficient for providers to make informed decisions about whether to offer the testing or for patients to make decisions about whether to accept it. Mathematical modeling of these predictive values from preliminary studies in an artificially composed population with a disease frequency on the order of 1 in 8 is very different from a demonstration of the true performance of the testing in a validation study of actual use in a large population with a disease frequency of 1 in 200 . We did not suggest that the testing was unreliable because it is not FDAapproved. We did point out that current regulations permit marketing of laboratory-developed tests without the need to demonstrate their clinical validity.

The study by Futch et al. cited by Sehnert et al. had not yet been published when we finalized our article. This is the type of large study that will provide the data needed to calculate all the performance characteristics that we called for in our article. These published data are reassuring, but we note that the delivery dates for only half of the investigators' tested cohort had passed by the time of publication. Thus, ascertainment of outcomes is incomplete, and positive and negative predictive values are not yet calculable.

Michael F. Greene, M.D.

Massachusetts General Hospital

Boston, MA

Michelle M. Mello, J.D., Ph.D.

Harvard School of Public Health

Boston, MA

Stephanie Morain, M.P.H.

Harvard University

Cambridge, MA

Since publication of their article, the authors report no further potential conflict of interest.

DOI: $10.1056 / N E J M c 1311604$

\section{The Great East Japan Earthquake and Out-of-Hospital Cardiac Arrest}

TO THE EDITOR: The most powerful earthquake ever recorded in Japan, with a magnitude of 9.0 on the Richter scale, struck the northeast region of Japan on March 11, 2011 (Fig. 1A)., ${ }^{1,2}$ Earthquakes are known to increase the risk of sudden cardiac arrest. ${ }^{3}$ Using a nationwide populationbased database, we assessed the association between this earthquake and the occurrence of outof-hospital cardiac arrest of presumed cardiac origin. ${ }^{4,5}$

Our study involved adult patients with out-ofhospital cardiac arrest of presumed cardiac origin who were transported to medical institutions in Iwate, Miyagi, and Fukushima - the three prefectures that were most damaged by the earth- quake (Fig. 1A). The study included data from 4 weeks before to 8 weeks after March 11 in each year from 2005 to 2011. Weekly changes in the occurrence of out-of-hospital cardiac arrest after the earthquake were assessed with the use of Poisson regression models to calculate risk ratios comparing the observed numbers of patients with out-of-hospital cardiac arrests in each week with the expected numbers of such events. Expected numbers of events were estimated with the use of data from 2005 to 2010 on the number of events, according to the weekly average ambient temperature, the week, and the year during that period. Risk ratios were also calculated according to sex and age group. 


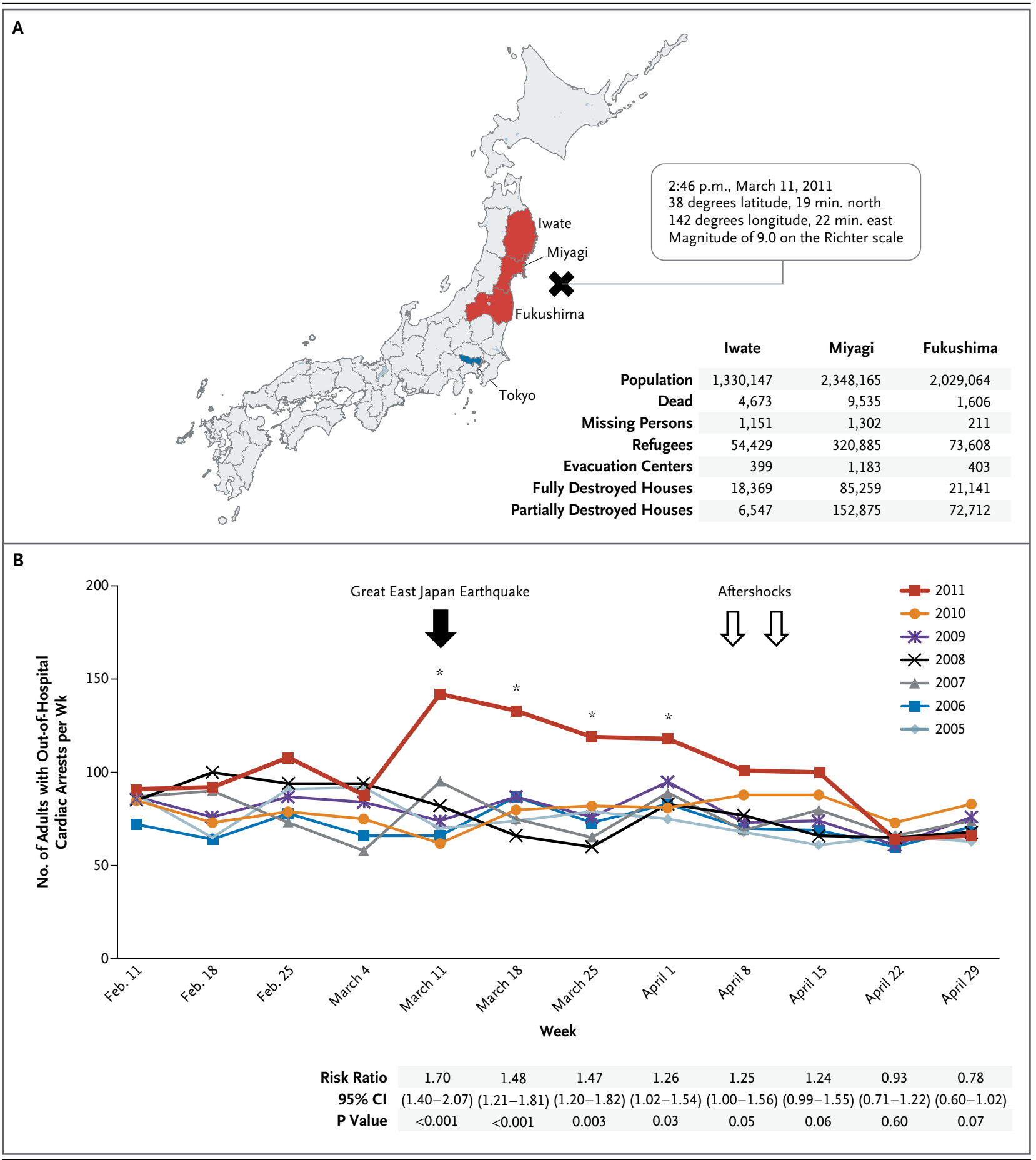

A total of 6733 adults were confirmed to have out-of-hospital cardiac arrest was significantly out-of-hospital cardiac arrest of presumed car- increased in the first week (risk ratio, 1.70), secdiac origin in the three prefectures. The risk of ond week (risk ratio, 1.48), third week (risk ra- 
Figure 1 (facing page). Characteristics of the Great East Japan Earthquake and the Number of Adults with Outof-Hospital Cardiac Arrests of Presumed Cardiac Origin in the Three Most Affected Prefectures.

Panel A shows a map of Japan that highlights the areas most affected by the earthquake. The epicenter (indicated with the letter $X$ ), the three prefectures included in this study (red), and the city of Tokyo (blue) are shown. The data in the inset show the extent of disaster damage in each of the three prefectures. Population data are from the 2010 Japan census. The numbers of persons who died or were missing and the numbers of fully or partially destroyed houses were reported as of March 2013. The numbers of refugees and evacuation centers were the peak numbers reported as of March 2013. Panel B shows the day of the earthquake (black arrow) and the days of maximum aftershocks (magnitude of 7.2 on April 7 and 7.0 on April 11) (white arrows). The risk ratios with corresponding $95 \%$ confidence intervals for the occurrence of out-of-hospital cardiac arrest after the earthquake, according to week, are shown. Asterisks denote $\mathrm{P}<0.05$ for changes in the occurrence of out-of-hospital cardiac arrest of presumed cardiac origin after the earthquake, according to week. $\mathrm{Cl}$ denotes confidence interval.

tio, 1.47), and fourth week (risk ratio, 1.26) after the earthquake (Fig. 1B). The risk of out-ofhospital cardiac arrest did not increase significantly among men between the ages of 18 and 74 years (see Fig. 1 in the Supplementary Appendix, available with the full text of this letter at NEJM.org), but it did increase significantly among women in the same age group during the first 2 weeks after the earthquake (Fig. 2 in the Supplementary Appendix). Among men 75 years of age or older, the risk of out-of-hospital cardiac arrest increased during the first 2 weeks after the earthquake and again in the first week after maximum aftershocks with a magnitude of 7.2 on April 7 and 7.0 on April 11 (Fig. 3 in the Supplementary Appendix). Among women 75 years of age or older, the risk was increased in the first, third, and fourth weeks after the earthquake (Fig. 4 in the Supplementary Appendix).

Tetsuhisa Kitamura, M.D.

Osaka University

Osaka, Japan

Kosuke Kiyohara, Dr.P.H.

Tokyo Women's Medical University

Tokyo, Japan
Taku Iwami, M.D., Ph.D.

Kyoto University Health Service

Kyoto, Japan

iwamit@e-mail.jp

Disclosure forms provided by the authors are available with the full text of this letter at NEJM.org.

1. Japan Meteorological Agency. The 2011 off the Pacific coast of Tohoku earthquake (http://www.seisvol.kishou.go.jp/eq/2011_03 _11_tohoku/index.html). (In Japanese.)

2. National Police Agency of Japan. Damage situation and police countermeasures (http://www.npa.go.jp/archive/keibi/biki/ higaijokyo_e.pdf). (In Japanese.)

3. Kario K, McEwen BS, Pickering TG. Disasters and the heart: a review of the effects of earthquake-induced stress on cardiovascular disease. Hypertens Res 2003;26:355-67.

4. Kitamura $T$, Iwami $T$, Kawamura $T$, Nagao $K$, Tanaka $H$, Hiraide A. Nationwide public-access defibrillation in Japan. N Engl J Med 2010;362:994-1004.

5. Ambulance Service Planning Office of Fire and Disaster Management Agency of Japan. Effect of first aid for cardiopulmonary arrest (http://www.fdma.go.jp/neuter/topics/houdou/h24/ 2411/241130_1houdou/02_houdoushiryou.pdf). (In Japanese.)

DOI: $10.1056 / N E J M c 1306058$

Correspondence Copyright $\odot 2013$ Massachusetts Medical Society.

\section{INSTRUCTIONS FOR LETTERS TO THE EDITOR}

Letters to the Editor are considered for publication, subject to editing and abridgment, provided they do not contain material that has been submitted or published elsewhere. Please note the following:

- Letters in reference to a Journal article must not exceed 175 words (excluding references) and must be received within 3 weeks after publication of the article.

- Letters not related to a Journal article must not exceed 400 words.

- A letter can have no more than five references and one figure or table.

- A letter can be signed by no more than three authors.

- Financial associations or other possible conflicts of interest must be disclosed. Disclosures will be published with the letters. (For authors of Journal articles who are responding to letters, we will only publish new relevant relationships that have developed since publication of the article.)

- Include your full mailing address, telephone number, fax number, and e-mail address with your letter.

- All letters must be submitted at authors.NEJM.org.

Letters that do not adhere to these instructions will not be considered. We will notify you when we have made a decision about possible publication. Letters regarding a recent Journal article may be shared with the authors of that article. We are unable to provide prepublication proofs. Submission of a letter constitutes permission for the Massachusetts Medical Society, its licensees, and its assignees to use it in the Journal's various print and electronic publications and in collections, revisions, and any other form or medium. 